\title{
Implementation and Improvement of the Argumentation System for Navigation Safety Influences of Water-Involved Projects
}

\author{
Wang Wei ${ }^{1,}{ }^{*}$, Li Youyou ${ }^{2}$ \\ ${ }^{1}$ School of Arts and Law.Wuhan University of Technology ,China \\ ${ }^{2}$ School of Arts and Law.Wuhan University of Technology ,China
}

*Email: 848710266@qq.com; 346249220@qq.com

\begin{abstract}
The argumentation of navigation safety influences of water-involved projects is aimed to remove hidden navigation safety dangers in the form of management in advance, thus being an effective way of managing navigation safety. Since implementation of the system, it has played an active role in reducing water-borne traffic accidents, enhancing the entire shipping efficiency and improving comprehensive utilization efficacy of water resources but the following aspects need to be completed, including increasing legal basis level, confirming the organizer status of maritime affairs institutions, clarifying scope of water-involved projects, safety argumentation contents, qualification of intermediaries and responsibilities of relevant parties.
\end{abstract}

Key words: navigation safety, argumentation.

Navigation safety is directly related with navigation environment. Increasing water-involved projects such as bridge and wharf which have emerged with economic growth exert two-way influences over the navigation environment. Once it's established, it will be hard to reverse its influences. Management in advance is an effective means of avoiding and reducing deteriorating navigation environment in water-involved projects. It's generally believed that the issuance of "Regulations on Navigation Safety of Water-Borne and Underwater Activities" in 2011 marked that China officially set up its own argumentation system for navigation safety influences of water-involved projects. On the occasion of "Maritime Traffic Safety Law" revision, it's of great significance to review implementation of the system and propose suggestions on system improvement.

\section{Contents of the Navigation Safety Influence Argumentation System}

Navigation safety influence argumentation is initial judgment of water-involved projects' influences over navigation safety. It doesn't have independent space and is a necessary condition for initiation and approval of water-involved projects.

The scope of navigation safety influence argument is "water-involved projects which need approval as required by state regulations and might impact navigation safety" and objects which launch the argumentation procedure need to satisfy the following conditions: ${ }^{1}$ it must be water-involved projects; (2) state approval management; ${ }^{3}$ possible influences over navigation safety. The argumentation time is water-involved project approval stage and argumentation results are whether projects are approved or not, how to construct and what to construct. The bases for argumentation are shipping development planning, port development planning and shipping traffic situation to make sure water-involved projects are match the planning and status quo; the focus of argumentation is the operation safety of the project itself and permanent impact on the navigation environment.

\section{Implementation Value and Effect of the Navigation Safety Influence Argumentation System}

Navigation safety influence argumentation objectively analyzes risks existing in project design and construction, pertinently puts forward measures of removing or reducing risks, realizes risk pre-control to the greatest extent, reduces hidden safety dangers of project construction from the source, and minimizes the negative impact of projects on maritime navigation environment; at the same time, it can improve utilization efficiency of water-involved projects and comprehensive 
utilization efficiency of water resources, and boost regional and social economic growth on the whole.

According to traffic industry development reports announced by Ministry of Transport, ever year, hundreds of transport ship maritime accidents take place in China (see table 1) and the traffic safety situation is not promising. Some accidents are related with water-involved projects, such as Dalian Newport pipe laying explosion in July 2010; the collision of "Nanguiji 035" bow with the pier of Guangdong Jiujiang Bridge in June 2007. Navigation safety argumentation can remove hidden navigation safety dangers of water-involved projects and reduce occurrence of accidents.

\begin{tabular}{|c|c|c|c|c|}
\hline $\begin{array}{l}\text { Project } \\
\text { Pear }\end{array}$ & $\begin{array}{l}\text { Number of } \\
\text { accident } \\
\text { (piece) }\end{array}$ & $\begin{array}{l}\text { Number of death } \\
\text { and missing } \\
\text { (person) }\end{array}$ & $\begin{array}{l}\text { Sunk (totally } \\
\text { damaged) ship } \\
\text { (ship) }\end{array}$ & $\begin{array}{l}\text { Direct economic } \\
\text { loss (hundred } \\
\text { million yuan) }\end{array}$ \\
\hline 2014 & 260 & 247 & 141 & 2.59 \\
\hline 2013 & 262 & 265 & 142 & 3.84 \\
\hline 2012 & 270 & 277 & 165 & 4.66 \\
\hline 2011 & 298 & 291 & 175 & 3.90 \\
\hline 2010 & 331 & 329 & 195 & 3.24 \\
\hline
\end{tabular}

Note: Data in this table comes from the sub-column of industrial bulletin of the bulletin column on the website of Ministry of Transport.

\subsection{Enhance Entire Shipping Efficiency}

The reform and opening-up has injected vitality into the economy. High-speed economic growth for many years in succession has amplified the demand for shipping. Water-involved projects which are the foundation for shipping have been quickly developed, mainly demonstrated in increasing construction scale and quantity. Meanwhile, available coastlines with favorable natural conditions have been constantly reduced and project site selection and construction become more and more difficult. Construction and shipping cost will rise if pre-stage navigation safety argumentation is not conducted. In 2008, PetroChina had to re-select the site for its LNG project because it didn' t full consider safety requirements of LNG ship arrival and departure for shipping channel and anchorage ground as well as unfavorable impact of the project on the entire Pearl River Delta port cluster, thus paying an immense price; take another established port for example. Due to insufficient consideration for navigation safety, entry of large ships needs at least three towboats, which leads to rising shipping cost and weakens the port's competitiveness. In the end, remedial action had to be taken to perfect the navigation environment. ${ }^{[1]}$

\subsection{Improve Comprehensive Utilization Efficacy of Water Resources}

Water resources have multiple value so great differences exist in purposes of water-involved projects. The demand for clean energy has escalated maritime platform and hydraulic electric generation projects; considering comprehensive traffic, sea, river and stream spanning bridges are constantly built. Unceasing appearance of large permanent maritime projects will produce proactive results if influences over navigation safety can be considered comprehensively; otherwise, negative effect will be generated.

Hangzhou Bay Bridge which was completed and open to traffic in May 2008 created the outstanding performance of "zero navigation accidence for six years" because of considerate thoughts about navigation safety and powerful supervision; the pier of a water-spanning bridge within the governance of Shenzhen Marine Bureau adopted the "pyramid" design. Partial width under the water is greater than that of what' $s$ above the water. In this way, a "underwater reef" was formed. It increased the possibility of navigation accidents and dramatically made supervision of maritime management department more difficult as well as adding more workload. After the water storage of Dadingzi Shandong Air electrical hub project, the navigation conditions of waters of over $100 \mathrm{~km}$ above the dam were improved and numerous shallow and dangerous water channels were removed. Meanwhile, certain changes took place in the water level rising and falling and sediment movement in waters over $70 \mathrm{~km}$ downstream of the Songhua River, which deteriorated the navigation environment and left hidden navigation safety dangers. ${ }^{[2]}$ 


\section{Implementation Effect}

\subsection{Realize Coordination with "Waterway Law"}

"Waterway Law" highlights "navigation conditions" and "Maritime Traffic Safety Law” pays attention to "navigation safety" . Each of them has its own focus. While "Waterway Law" confirms the waterway navigation condition influence evaluation system, it can better realize legal coordination to approve currently implemented navigation safety influence argumentation system in

"Maritime Traffic Safety Law" . Fig. 1 shows that 78.3\% maritime management staff maintains that the waterway navigation condition influence evaluation system is conducive to guaranteeing navigation safety.

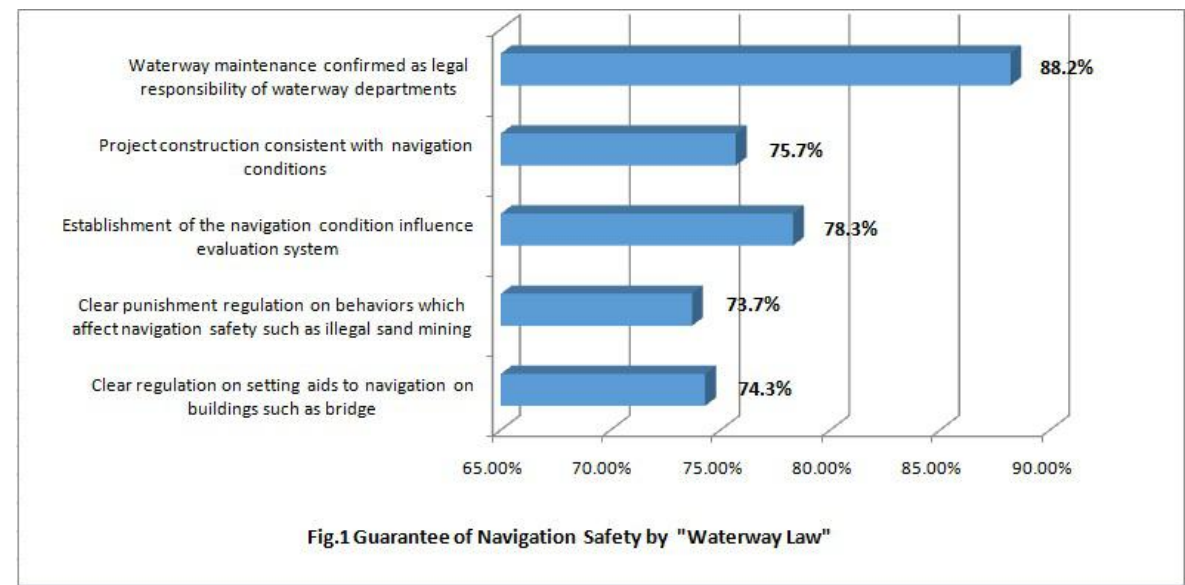

\subsection{Approved by Project Proprietor}

As the state constantly strengthens safety requirements and proprietors' safety awareness is increasingly improved, discovering risks existing in project design through navigation environment influence evaluation and timely optimizing design plans can reduce risks during construction period and operation period. During the phase II supporting wharf project approval by Guangzhou Green Oil Grease Industrial Co., Ltd soon after the implementation of the system, navigation safety influence argumentation gave well scope to its scientific management function. Objective problems existing in the project were found out and besides directions and methods were pointed out, thus being highly approved and lauded by project proprietors. ${ }^{[3]}$

\subsection{Promote Development of Intermediaries}

As the reform of China' $s$ administrative and public institution units is accelerated, especially establishment and development of the market economic system, varied professional service agencies have emerged at the right moment. Maritime management institutions only perform their right of reviewing argumentation reports rather than directly participating in the argumentation process so project proprietors can choose qualified intermediaries on their own to conduct concrete argumentation work, thus providing a possibility for socialized and marketized argumentation service market; at the same time, intermediaries are accumulating experience in such service, enhancing service level and efficiency, and facilitating its own development owing to expansion of their business scope.

\section{Suggestions on Improvement of Navigation Safety Influence Argumentation}

\subsection{Stipulate the Argumentation System in "Maritime Traffic Safety Law"}

"Production Safety Law" established the safety evaluation system and stipulated "for separate regulations on maritime traffic safety in laws and administrative regulations, such regulations are applicable" ; "Waterway Law" set up the navigation condition influence evaluation system; "Port Law" established the environment influence evaluation system. However, the legal basis for implementation of water-involved navigation safety influence argumentation system is only at the 
level of department rule, which restrains effective implementation of the system. Therefore, it' $\mathrm{s}$ necessary to add the system in "Maritime Traffic Safety Law" .

\subsection{Establish the Organizer Status of Maritime Management Institutions}

Navigation environment influence argumentation is a technical support system with strong professionalism. At present, implementation of the system is arranged by the National Development and Reform Commission and maritime management institutions which are in charge of navigation safety turns into a supporting role. Its professional opinions cannot be accepted or adopted sometimes. Such arrangement has broken current division of labor, goes against the management principle of "who' $\mathrm{s}$ in charge takes the responsibility" and weakens management of navigation safety. Accordingly, it' $s$ necessary to clarify the organizer status of maritime management institutions in navigation safety influence argumentation and confirm direct efficacy of opinions issued by maritime management institutions about project approval and construction.

\subsection{Clarify the Scope of Water-Involved Projects}

"The meaning of "may generate influences over navigation safety" shall be clearly stated. Investment sum standards and project type standards shall be worked out to elaborate concrete projects which need navigation safety influence argumentation. Regulations in "Waterway Law" can be drawn upon to exclude water-involved projects which don' $t$ need navigation safety influence argumentation. Such regulations not only provide explicit management basis for maritime management institutions but also ensure clear expectation of proprietors.

\subsection{Clarify Contents of Safety Argumentation}

References are provided for report writers by analyzing existing argumentation, combing problems in practice, re-draft contents of navigation safety influence argumentation and offering standard "Argumentation Report” template. At the same time, the cohesive relation between the argumentation and other evaluation systems shall be taken into account to reduce overlapping evaluation contents or clarify the application efficacy of prior evaluation contents.

\subsection{Clarify Qualification Conditions of Assessment Institutions}

"Maritime Traffic Safety Law" shall stipulate explicitly conditions which assessing institutions should possess according to requirements of navigation safety influence argumentation in order to ensure due quality of assessment reports. Maritime management institutions don' t impose a quantity limit on assessing institutions, adopt the system similar to the review system of corporate registration at the industry and commerce bureau and timely announce institutions which obtain assessment qualification to ensure formation of the assessment market.

\subsection{Clarify the Responsibility System of Safety Argumentation}

Responsibilities of relevant parities in the process of implementing the navigation safety influence argumentation system include maritime management institutions and their working staff, assessment institutions and their working staff, project construction units and their principals as well as possible subjects shall be made clear when violating laws and regulations. The realization of the system purposes shall be ensured via compensation and punishment methods.

\section{References:}

[1] LI Huaguo, TUO Peilin, and KONG Xianwei, On the Necessity of Strengthening Navigation Safety Influence Argumentation at Approval Stage of Water-Involved Projects :submitted to China Maritime Safety(2012).

[2] FENG Haizhong,Causes for Impact of Waterborne Projects Construction on Navigation Safety :submitted to Applied Energy Technology(2005).

[3] Information on http://www.zhinengjiaotong.com. 